\title{
CUADERRMQQ
}

\section{EL PLAN DEL 80 EN SANTA FE: REGIONALIZACIÓN TARDÍA ANTE UNA SUBURBANIZACIÓN INMINENTE}

\section{Gisela Ariana Rausch}

Arquitecta graduada de la Facultad de Arquitectura, Diseño y Urbanismo, de la Universidad Nacional del Litoral. Docente ordinaria por Concurso Nacional. Cargo: Ayudante de Cátedra en la asignatura Teorías y Producción arquitectónica en el siglo XX e investigadora en el Instituto de Teoría e Historia Urbano arquitectónica (INTHUAR), de la Universidad Nacional del Litoral. Entre 2007 y 2010, becaria de la Agencia Nacional de Promoción Científica y Técnica (ANPCyT) en el marco del Proyecto Observatorio Urbanístico del Área Metropolitana Santa Fe-Paraná y desde 2010, becaria del CONICET. Desde 2007 lleva adelante estudios de Doctorado en Humanidades y Artes, mención Historia, en la Universidad Nacional de Rosario. giselarausch@conicet.gov.ar / giserausch@gmail.com 


\title{
Artículos Arbitrados
}

CUADERNO URBANO. Espacio, Cultura, Sociedad - VOL. 9 - № 9 (Octubre 2010) pp. 111-129. ISNN 1666-6186

\begin{abstract}
Resumen
Se intenta una aproximación al Plan Urbano de 1980 de la ciudad de Santa Fe, el cual puede ubicarse dentro de la serie de planes con voluntad de regionalización, que tuvieron lugar en parte de Argentina entre las décadas del 40 y el 60. De publicación tardía, durante el gobierno de facto de 1976-1983, el Plan se alineaba con lo que se dio en llamar planificación integral.
\end{abstract}

El abordaje del Plan tiene como objetivo principal volver la mirada hacia una herramienta de actuación urbana en la que por primera vez en la historia urbanística local se menciona la ocupación de las áreas periféricas de la ciudad. Cuestión que en los últimos años, frente el desborde suburbano que muchas ciudades intermedias argentinas han sufrido a partir de los 70, y en particular, frente al problema hídrico recurrente en Santa Fe, por la ocupación del valle del Paraná, continúa en mesa de debate.

\section{Palabras clave}

Planificación, ruralización, región.

\begin{abstract}
We attempt an approach to Santa Fe's Urban Plan of 1980, which could be included within a series of regionalization plans carried out in Argentina in the forties and sixties (seventies). Published belatedly, during the dictatorial military regime of 1976-1983, the plan was conceived within the concepts of what became known in parts of Argentina integrated planning.
\end{abstract}

The approach of this Plan aimed mainly to use an urban planning tool in which, for the first time, in the local urban history, peripheral areas are included as part of the city. These issues are still of concern, due to the urban sprawl a lot of intermediate cities have experienced, and specially in Santa Fe due to recurrent flooding of the city located on the alluvial valleys of the Paraná river.

\section{Keywords}

Planning, ruralization, region. 
Gisela Ariana Rausch

\section{EL PLAN DEL 80 EN SANTA FE: REGIONALIZACIÓN TARDÍA ANTE UNA SUBURBANIZACIÓN INMINENTE}

\section{INTRODUCCIÓN}

La historia de la disciplina urbanística en Santa Fe se ha ido constituyendo entre el olvido y la debilidad operativa. Olvido porque la mayor parte de los planes - dos de tres, para hablar con precisión - han quedado débilmente inscritos en la memoria disciplinar. Debilidad operativa porque ninguno de ellos ha podido superar la instancia de formulación, y su condición propia de herramienta para la actuación en la ciudad no ha llegado a efectivizarse con contundencia.

En más de un siglo, Santa Fe ha aprobado tres planes urbanos: el Plan del 27, que duró seis meses ${ }^{1}$, fue mal acogido por la prensa, su autor aún está entre signos de interrogación y fue firmado por un concejal de la Municipalidad²; el Plan Regulador de 1947, firmado por Miguel Roca, cuyo grandilocuente discurso progresista e higienista y el despliegue, por momentos vacuo, de pomposas imágenes reforzadas por la "verdad" estadística, sin duda quedaron inscripto en la memoria disciplinar, a juzgar por los estudios que de él se han realizado, y el Plan Director de 1980, una publicación tardía confeccionada en su mayor parte con ideas y estudios realizados más de una década antes, en la oficina de la Dirección de Planeamiento Urbano municipal, que además de recibir fuertes críticas en al ámbito académico específico de la disciplina fue prontamente dejado en el olvido.

Sin embargo, el Plan del 80 aún sigue vigente. ${ }^{3}$ Por un lado, es el último aprobado por Ordenanza Municipal № 7871 del 14 de agosto de 1980, y si bien aparece con un importante atraso - temporal-, es el primer plan de la ciudad que incorpora ideas y ciertas herramientas propias de lo que se dio en llamar a mediados del siglo XX Planificación integral, incorporando el concepto de región.

Por otro lado, su vigencia consiste en que plantea una serie de cuestiones que hoy más que nunca están en discusión, como por ejemplo: la ocupación del albardón costero perteneciente al valle de inundación del río Paraná - llamado área de la costa-, la relocalización de las instalaciones portuarias y la ampliación de usos en las instalaciones existentes, la localización del parque industrial, la sistematización del tránsito y la descongestión del Boulevard Gálvez.
2- Julio C. Cabal firmó el plan del cual se dijo habia sido Durand el autor. Sin embargo, hay discusiones sobre esta cuestión, habiendo quien considera que el plan fue confeccionado por Ángel Guido. Sobre el tema, ver: FEDELE, J. Ciudad y río: la construcción histórica de un paisaje (1886 1952). Tesis doctoral. Santa Fe-
Barcelona, 2009; p. 227-235.

3- Si bien actualmente se está llevando adelante el Plan Estratégico 2008, éste tiene carácter provincial y por lo tanto no puede considerarse dentro de la serie de planes de la ciudad. 


\section{Artículos Arbitrados}

CUADERNO URBANO. Espacio, Cultura, Sociedad - VOL. 9 - № 9 (Octubre 2010) pp. 111-129. ISNN1666-6186

4- Ver: ARÓSTEGUI, Julio. La historia vivida. Sobre la historia del presente. Madrid: Alianza, 2004; ARÓSTEGUI, Julio; BUCHRUCKER, Cristian y SABORIDO, Jorge (Dir.). El mundo contemporáneo: historia y problemas. Buenos Aires: Biblós, 2001.

5- KOSELLECK, Reinhart. Futuro Pasado. Para una semántica de los tiempos históricos. Barcelona: Paidós Básica, 1993.

6- El plan quedaría en la memoria como el "Plan Nardi", aunque dicho arquitecto ya había que dicho arquitecto ya habia to al momento de su publicación.
El planteamiento metodológico de este abordaje puede situarse dentro de lo que se define como historia del presente, según la concepción desarrollada por el historiador español Junio Aróstegui ${ }^{4}$, muy en la línea propuesta por Reinhart Kosselleck. ${ }^{5}$ Las fuentes utilizadas fueron entrevistas, artículos periodísticos y documentos de primera mano obtenidos en el archivo de la Dirección de Planeamiento Urbano Municipal, en el archivo de Catastro municipal y en diversas bibliotecas.

\section{EL PLAN: BREVE RESEÑA DE SU LARGA PREPARACIÓN}

Para RigotTr, la disciplina urbanística en Argentina se constituyó en sucesivas invenciones, "mutando en sus representaciones, en sus fundamentos epistemológicos, en sus formas de ver y enunciar para hacer" (RigotTi, 2003:4). Invención en el sentido de creación, o más precisamente, como la autora lo explicita — citando a De CERTEAU — invención como reapropiación en el consumo (DE Certeau, 2000). Consumo de algo existente, desde luego, pero creación, a partir de ello, de algo nuevo, ligado al particular uso - o consumo, para ser precisos- de los elementos y materiales disponibles. Eso por un lado. Por otro, las mismas condiciones de existencia en las cuales la disciplina urbanística se fue desarrollando, se fueron aplicando y probando sus herramientas, se encargó de darle particular forma a dichas invenciones, conformando un campo disciplinar heterogéneo, complejo, y como precisa RigotTI, refiriéndose al Urbanismo en Argentina: lábil (RIGOTTI, 2003). En este sentido, cualquier estudio sobre el desarrollo de la disciplina implicará echar más que un vistazo a la cocina de tales invenciones. En el producto nunca podrán trazarse líneas de inteligibilidad sin un detenimiento en los elementos implicados en su preparación, en las particulares combinaciones, en las relaciones con otros objetos-invenciones, sin olvidar, por supuesto, las condiciones históricas del medio desde el cual surge. El Plan del 80 constituyó el producto de los trabajos realizados desde finales de la década del 60 y toda la década del 70 por la Oficina de Planeamiento Municipal de la ciudad de Santa Fe.

En el año 1966 se forma la Dirección de Planeamiento Urbano municipal con el fin de confeccionar un Plan Urbano para la ciudad. Como directores asumen los arquitectos Norberto Nardi ${ }^{6}$ y Waldemar Giacomino compartiendo el cargo.

Giacomino, que al momento de ganar el concurso contaba con no poca experiencia en planificación urbana, había realizado sus estudios de grado, como arquitecto, en la Uni- 
Gisela Ariana Rausch

\section{EL PLAN DEL 80 EN SANTA FE: REGIONALIZACIÓN TARDÍA ANTE UNA SUBURBANIZACIÓN INMINENTE}

versidad de Rosario y había establecido un duradero contacto con Jorge Hardoy (profesor del Taller de Arquitectura 6 y director del IPRUL). Desde 1962 hasta finales de 1965, Giacomino trabajó en un estudio de planificación urbana, en París, por el cual, un año antes, había pasado también José Pastor?. Allí, Giacomino había intervenido en el Plan de desarrollo para la costa francesa sobre el Mediterráneo, la costa de Roussillon. Dicho Plan estaba inscripto dentro del Quinto Plan de De Gaulle. En 1964, dentro del mismo estudio de planificación, Giacomino se hace cargo, junto con otro arquitecto, del ordenamiento de una serie de poblaciones dentro de lo que fue el Plan de Desarrollo para la Estación Turística de Aber, también en Francia, que incluía a toda la región de Aber conformada por una serie de ciudades de escala menor, a las cuales se intentaba desarrollar socioeconómicamente más allá de la estación específica, que funcionaría como polo turístico. A finales de 1965 Giacomino vuelve a Argentina, donde se postula para el cargo de director de la Oficina de Planeamiento Urbano, de la Municipalidad de Santa Fe.

De Norberto Nardi se sabe que adquirió experiencia disciplinar en Puerto Rico. Hay que considerar que ya para la década del 60, Puerto Rico contaba con una escuela en planificación, la Escuela Graduada en Planificación -fundada en 1965, pero que venía haciendo trabajos previos de capacitación - y la experiencia de la Junta de Planificación de Puerto Rico. Este país en los 60 ya era, podría decirse, un país potente en materia de planificación que seguía la línea del planning norteamericano y las máximas del New Deal ${ }^{8}$, siendo la reestructuración de la cuenca del valle de Tennesse, quizás, el exponente más significativo, que ya en 1933 sienta principios, métodos y modelos de estructuras organizativas, conformando una imagen que, como dice SICA, "viene a consagrar la intervencióny el papel del Estado en la resurrección-reestructuración del capitalismo" (SICA, 1981:689-690).

En consecuencia, la Oficina de Planeamiento para el Municipio de Santa Fe se forma con dos figuras cuyas experiencias se asentaban, por un lado, en la tradición francesa de la planificación que ya tenía más de medio siglo de vigencia, y por el otro, en las propuestas que habían sido implementadas en Puerto Rico, de corte fuertemente norteamericano. Poco tiempo después se incorpora como dibujante el arquitecto Edgardo Gambini, el cual en los 80, en el momento de publicación del Plan, ocupará el cargo de director de la oficina.

Una vez formado el equipo de planeamiento, se iniciaron trabajos de diagnóstico: principalmente tareas de coordinación y reunión de las diferentes reparticiones municipales
7- Por cierto, en el estudio parisino, tenían una opinión de Pastor bastante negativa, y se referían a él como un "personaje raro", que rozaba lo ridículo.

8- El llamado New Deal adoptó la forma de un fuerte populismo tecnocrático, apelando a la tecnocrático, apelando
participación del pueblo. 


\section{Artículos Arbitrados}

CUADERNO URBANO. Espacio, Cultura, Sociedad - VOL. 9 - № 9 (Octubre 2010) pp. 111-129. ISNN1666-6186

9- Algunos años más tarde esta comisión participará del Proyecto hidroeléctrico Paraná Medio, que estará más de una década en discusión y no llegara década en discusión y no llegará nunca a concretarse. Dicho proyecto se habia realizado dentro del Proyecto del río Bermejo.
(Dirección de Obras Públicas, Secretaría de transporte, Dirección de Puertos, etc.), así como también actividades para el establecimiento de contactos con organismos de carácter nacional (CONADE, Vialidad Nacional, Ferrocarriles), provincial (COPRODE, Vialidad Provincial) e incluso internacional (Comisión de la Cuenca del Plata).

Las relaciones tanto con el CONADE (Consejo Nacional de Desarrollo) como con el COPRODE (Consejo Provincial de Desarrollo) tenían como objetivo inscribir las acciones de planeamiento dentro de un Plan mayor, nacional. La Comisión de la Cuenca del Plata era una organización que intentaba reunir todas las urbanizaciones de los diferentes países pertenecientes al territorio de la cuenca. La comisión contaba con un representante en Santa Fe, Lorenzo García, y realizó uno de sus congresos en la ciudad, pero sus actividades se fueron diluyendo progresivamente y no se pudo llegar a acciones de mayor relevancia. ${ }^{9}$

Las actividades que se realizaron en la oficina durante los primeros cinco años consistieron, por un lado, en acciones de "concientización" de los habitantes de la ciudad y las diferentes organizaciones, sobre la necesidad de planificación y el trabajo en equipo, tanto de las reparticiones y organismos públicos como de asociaciones específicas.

De manera que la Oficina de Planeamiento se ubicó dentro de un Plan mayor de organización a nivel nacional y localmente intentó coordinar fuerzas provenientes de diferentes organismos siguiendo lineamientos que claramente remiten a las prácticas propias del New Deal, o planificación democrática , ideas muy difundidas en Argentina por José Pastor y Jorge Hardoy.

Por otro lado, se llevaron adelante estudios dentro del municipio de Santa Fe, para relevar los aspectos físicos, sociales y económicos. Para ello, se contaba con un grupo de especialistas en estadística y sociología por una parte, y especialistas en economía, por otra. El equipo circunscribió sus estudios a la ciudad de Santa Fe y el área de la costa hasta San José del Rincón, que por ese momento aún pertenecía a la jurisdicción municipal. A cargo de los arquitectos quedaría el armado de la documentación referida a los aspectos físico-urbanos.

En el año 1968 se lleva a cabo el primer relevamiento fotográfico de la ciudad, con carácter científico. Si bien la Fuerza Aérea de Paraná había tomado algunas fotografías con 


\section{Gisela Ariana Rausch}

\section{EL PLAN DEL 80 EN SANTA FE: REGIONALIZACIÓN TARDÍA ANTE UNA SUBURBANIZACIÓN INMINENTE}

anterioridad, no se trataba de fotogrametrías. A partir de dicho relevamiento, en el mismo año sale el plano de restitución. ${ }^{10}$

En 1974, el arquitecto Giacomino deja la Oficina para tomar el cargo de Director de Servicios Públicos, con lo cual seguirá ligado a los trabajos de Planeamiento, principalmente por el tema del transporte, que en ese momento en la capital santafesina era estatal. Tiempo después, deja también la Oficina de Planeamiento el director, Nardi, y asume como director Gambini, quien será responsable del Plan junto con los arquitectos Luis Amavet, Sara Julierac y Oscar Berlincourt. El Plan será aprobado el 14 de agosto de 1980, es decir, catorce años después de la formación de la Oficina de Planeamiento.

\section{DOS IDEAS FUERTES DE DÉBIL DESARRO- LLO}

Dos ideas se destacan en el Plan y constituyeron los puntos de partida: por un lado, las nociones de planificación integrada y de región, implicadas tanto en las actividades de diagnóstico como en las propuestas de comunicación vial, y por otro lado, la voluntad de darle al río sobre la margen Este - la laguna Setúbal principalmente - un rol primordial en la configuración de la ciudad, pero también en la vida de los habitantes. Cuestión que, aunque de una manera más modesta, ya había sido expresada en el Plan del 27 y reforzada en el Plan Roca.

El río en el Plan: conciliación de lo urbano y lo rural

La ciudad de Santa Fe tiene una larga tradición en cuanto a intentos para establecer los ríos que la circundan como piezas fundamentales a partir de las cuales estructurar los espacios de la ciudad (FEDELE, 2009).

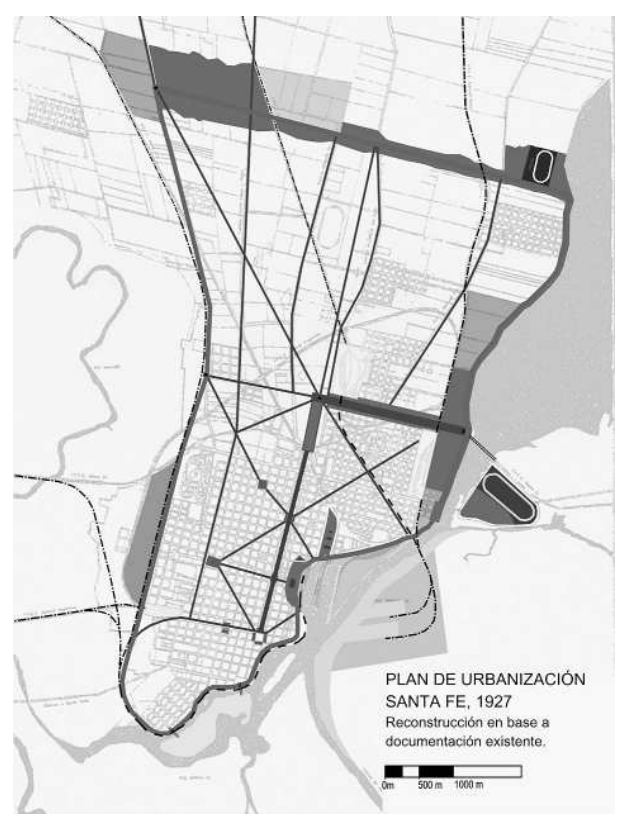

10- En el Archivo de Catastro Municipal existen dos planos que dicen ser confeccionados a partir del relevamiento de 1968 . Un plano es del mismo año y otro de 1974, que cuenta con algunas actualizaciones.
1- Reconstrucción planimétrica del Plan de urbanización de 1927 firmado por Julio $C$. Cabal. Fuente: elaboración de Javier Fedele sobre la base de una reconstrucción de Adriana Collado; en: FEDELE, J. Ciudad y río: la construcción histórica de un paisaje (1886-1952). 


\section{Artículos Arbitrados}

CUADERNO URBANO. Espacio, Cultura, Sociedad - VOL. 9 - № 9 (Octubre 2010) pp. 111-129. ISNN1666-6186

$\overline{\text { 11- La laguna Setúbal pertenece }}$ al sistema fluvial del río Paraná.

12- Si bien el Plan Roca establecía la ocupación de la isla de Los Pozos, frente a la laguna Setúbal, pozos, Jrente a la laguna Setúbal, no dejaba de ser ésta una propuesta que actuaba como un "frente (cívico-recreativo) mejorado" de la ciudad, y lo mismo ocurría con la propuesta de área industrial al Oeste, se trataba de un frente ganado al río para uso productivo e instalación de infraestructura.

13- El Plan Nardi constituyó una serie de formulaciones para la ciudad que no superaron la instancia de propuestas publicadas en un folleto y una serie de láminas que se mantuvieron en la Municipalidad.
2- Ciudad de Santa Fe y área de la costa en el sistema fluvial del Fuente: imagen LAND SAT Servicio de catastro información territorial de la provincia de Santa Fe (2004)
El Plan del 27 proponía, de cara al río Paraná, la apropiación de un sector del frente fluvial Sur-Este para instalar un puerto de envergadura, en torno al cual se estructurarían una serie de espacios públicos de cara a la ciudad, y hacia el Norte, un paseo costanera enfrentado, laguna Setúbal ${ }^{11}$ mediante, un parque zoológico y un aeródromo que terminaban por definir la orilla oriental de la ciudad, reservando para la margen del río Salado, al Oeste, la cara menos atractiva de la ciudad: la zona industrial. (Imagen l)

El Plan de Roca, de 1947, continúa enfatizando las directrices del Plan del 27, definiendo en mayor grado las propuestas anteriores y reforzando el carácter infraestructural y de servicio de la orilla Oeste en contraposición al embellecimiento de la margen de la Setúbal.

En cuanto al Plan del 80, si bien continúa con tales intentos de darle a los ríos un rol esencial en la estructura urbana, ya no será sólo considerando la apropiación de los frentes costeros como lo hicieron las propuestas anteriores ${ }^{12}$, sino, por un lado, llevando el río al mismo interior de la vida urbana para el caso de la laguna Setúbal, y por el Oeste. mediante las canalizaciones proyectadas en el río Salado, apropiándose del área fluvial en la zona industrial y de servicio. (Imágenes 2 y 3 )

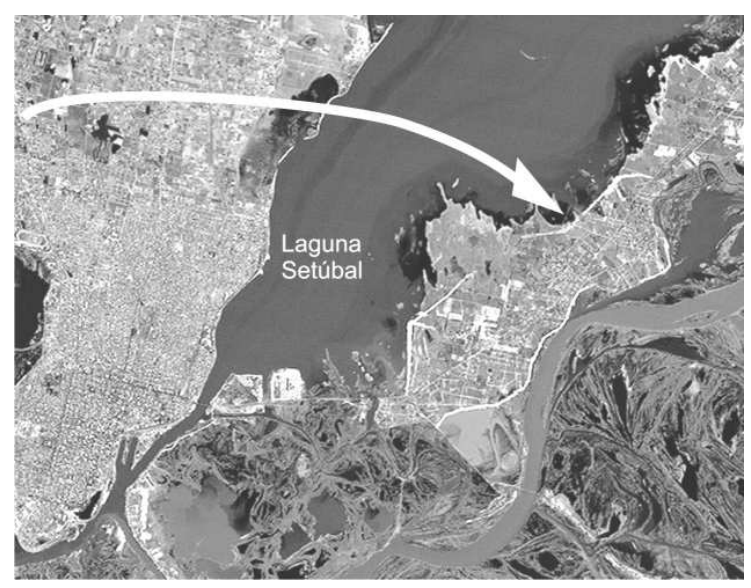

Esta intención había sido fuertemente promovida por los primeros responsables de la oficina de Planeamiento en las primeras formulaciones que se conocieron con el nombre de Plan Nardi. ${ }^{13}$ El Plan del 80 constituyó una reelaboración del Plan Nardi, y su propuesta, si bien no enfatizaba en la extensión hacia el Este de la ciudad, sí daba lugar o blanqueaba una situación que se estaba dando: la ocupación suburbana del albardón costero con casas de fin de semana y algunas instalaciones de intención turística. Así, el Plan del 80 establecía una comunicación 


\title{
Gisela Ariana Rausch
}

\author{
EL PLAN DEL 80 EN SANTA FE: REGIONALIZACIÓN TARDÍA ANTE UNA \\ SUBURBANIZACIÓN INMINENTE
}

entre la ciudad y el albardón a través de un cruce de la laguna ubicado al Norte de la ciudad, que se desprendía de la avenida de circunvalación proyectada. Esta avenida estaba pensada como colectora de los flujos regionales y vía de transición para ingresar desde las autopistas - concebidas como vías regionales - en la ciudad. La idea de este cruce retomaba, con una mínima variación en cuanto a ubicación, las propuestas que en 1959 ya se habían hecho como parte de las obras complementarias al Proyecto de canalización del río Bermejo $\mathrm{O}^{14}$, proyecto emanado del CONADE.

Otro cruce fluvial se proponía varios kilómetros más al Norte, comunicando las vías de acceso Norte a la ciudad con rutas de escala mayor y acompañando la comunicación ferroviaria que en el Proyecto del río Bermejo también aparecía en ese sitio, aunque sin cruzar el río, estableciendo comunicación con el cruce proyectado más al Sur. (Imagen 4)

Asimismo, el Plan realiza una sistematización vial en el albardón costero, proyectando una avenida costanera y la prolongación del terraplén de defensa contra inundación en los sectores que habían quedado sin defender.

La propuesta de alguna manera debilitaba la fuerte centralidad con que la ciudad había sido proyectada en los planes anteriores. El nuevo Plan promovía la ocupación de los sectores periféricos del Este isleño, haciéndolos parte de la ciudad y dejando (como lo habían hecho también los planes anteriores y el proyecto del Bermejo) el sector Oeste para la instalación del puerto, el parque industrial, infraestructura ferroviaria y el barrio obrero. ${ }^{15}$

La idea de extender la ciudad hacia el Este, problemática actualmente

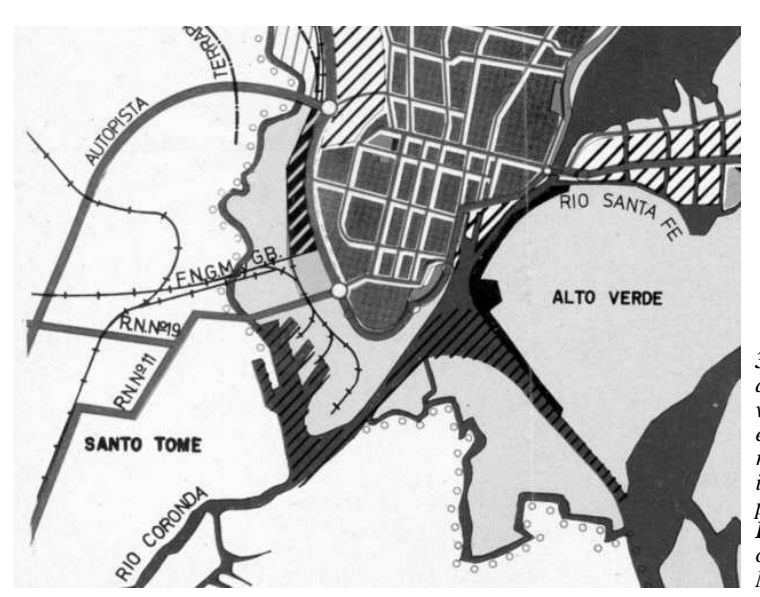

14- La Comisión del río Bermejo se constituyó para ejercer acciones y tomar decisiones respecto del aprovechamiento y explotación de los recursos hídricos pertenecientes a la Cuenca del río Bermejo, que abarca las provin Bermejo, que abarca las provin cias de Jujuy, Salta, Formosa,
Santiago del Estero, Entre Ríos y Santa Fe.

15- El Plan del 80 es el primero -y único hasta el momento - que proyecta el puerto en la margen Oeste, siguiendo el proyecto de desarrollo de la cuenca del Berdesarrollo de la cuenca del Ber mejo. El puerto que funciono hasta mediados del siglo $X X$ se encuentra al sur-este de la ciudad, en una zona de difícil acceso para embarcaciones ultrama rinas. Actualmente dicha área ha sido refuncionalizada hacia usos recreativos, y el puerto se ha relocalizado.
3- Fragmento de Plano síntesis del Plan Director de 1980. Puede verse al Sur-Oeste de la ciudad. el proyecto de canalización del río Salado como parte del área industrial y nuevo puerto proyectado.

Fuente: Plan Director de la ciudad de Santa Fe, 1980. Municipalidad de Santa Fe. 


\section{Artículos Arbitrados}

CUADERNO URBANO. Espacio, Cultura, Sociedad - VOL. 9 - № 9 (Octubre 2010) pp. 111-129. ISNN1666-6186

en debate, implicaba una nueva relación entre áreas urbanas y áreas rurales. Si en las propuestas del 27 y la del 47 el área periférica de la costa se concebía como tierra rural de reserva que no formaba parte de los proyectos del Plan, ahora, mediante el uso efectivo del río (laguna Setúbal), pero también a través de una sistematización vial y ferroviaria de las áreas por urbanizar, este sector adquiría un nuevo rol: como área de expansión urbana.

La planificación integrada y el concepto de región en el Plan

Los conceptos de planificación integrada y de región, que en el país ya circulaban en la década del 40, y la reconstrucción de San Juan había sido, sin duda, la mecha encendida que

4- Plano de anteproyecto de la desembocadura del Canal Santiago del Estero. Canales de río Bermejo y ot io Bermejo y obras complementarias Presidencia de la Nación, Comisión Nacional del río Bermejo. Plano $N^{\circ}$ 149. Escala

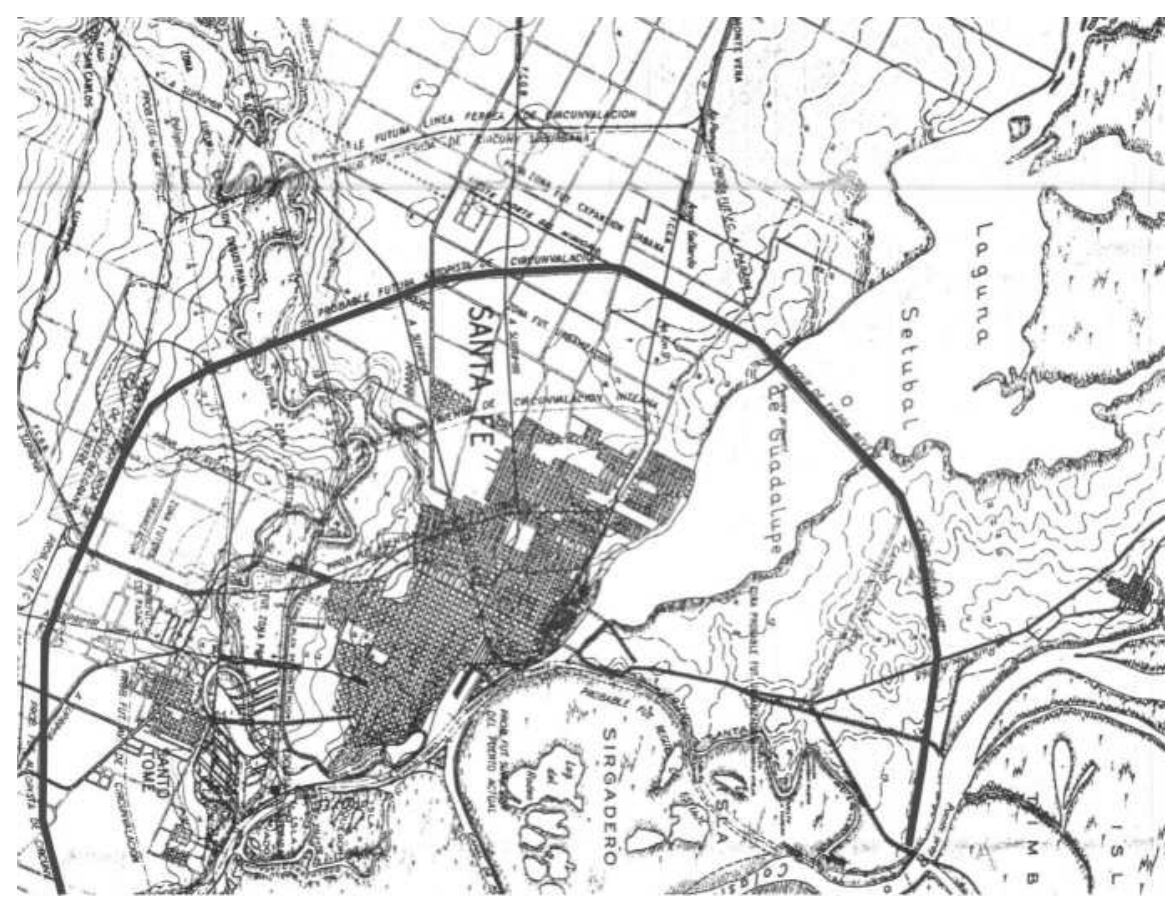




\section{Gisela Ariana Rausch}

\section{EL PLAN DEL 80 EN SANTA FE: REGIONALIZACIÓN TARDÍA ANTE UNA SUBURBANIZACIÓN INMINENTE}

abrió paso a su difusión. Como precisa Carlos Mazza: "La necesidad de apoyarse en directivas planificadas o en la programación de planes era y a predicada desde mediados de la década de 1930, proponiendo la planificación como mecanismo de transformación y a la vez de control del desarrollo económico y social del país." (Mazza, 2008:52). Sin embargo, estas ideas llegaron tardíamente a Santa Fe.

El gobierno peronista será el encargado de llevar adelante la concepción de un Estado promotor ${ }^{16}$ del desarrollo; así, continúa Mazza: “...el desarrollo social, la prevención de futuras crisis económicas y la situación del país en la inminente posguerra, la explotación de los recursos económicos y naturales, los problemas demográficos, la solución de la relación campo-ciudad y el apoyo a la incipiente

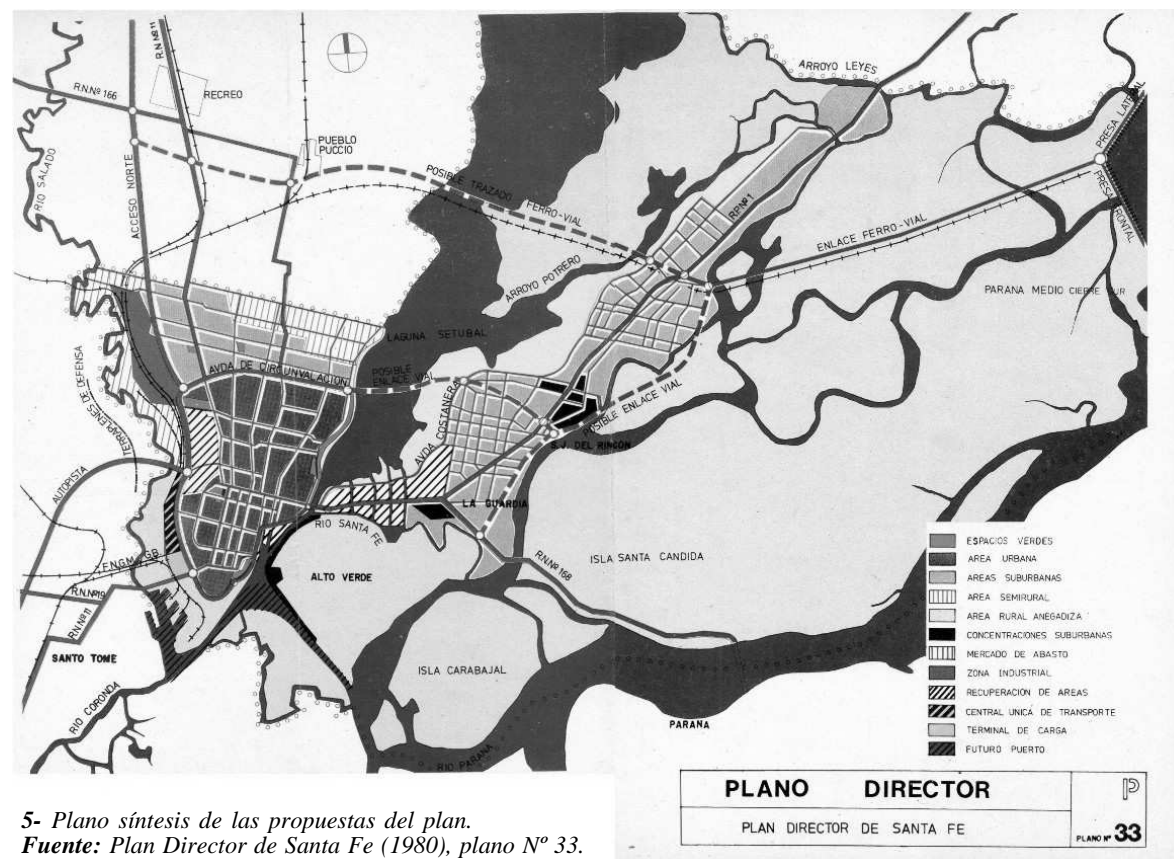

16- Durante el Segundo Plan Quinquenal se publicaron nueve planes, entre ellos: Plan Director de Transformación de Rosario (1953), Plan Orgánico para Tucumán (1951), Plan Regulador de Bahía Blanca (1950). Ver: RIGOT TI, A., 2003. 


\section{Artículos Arbitrados}

CUADERNO URBANO. Espacio, Cultura, Sociedad - VOL. 9 - № 9 (Octubre 2010) pp. 111-129. ISNN 1666-6186

17. CRAVOTTO fue el realizador del Anteproyecto de Plan Regulador de Montevideo. La memoria descriptiva fue publicada. Ver: CRAvotтo, M. "¿Qué quiere decir Instituto de Urbanismo de la Facultad de Arquitectura?", en: Revisa de Arquitectura, $N^{\circ} 259$. Bue nos Aires, julio de 1942; pp. 290 296. Publicación oficial, $N^{o} 1$. Instituto de Urbanismo, Facultad de Arquitectura. Montevideo, marzo de 1937; pp. 14-22; y también: Revista de Arquitectura, $N^{o}$ 178. Octubre, 1935.

18- JOSÉ PASTOR tuvo una activa participación en los debates de San Juan y sistematizó sus exposiciones y publicaciones en dos libros: San Juan, piedra de toque del planeamiento nacional, en 1945 y Urbanismo con planeamiento, de 1946

19- Traducción del alemán Kulturlandschaft. No se profundizará en este trabajo sobre el concepto de paisaje, sin duda por demás interesante y rico, pero que debido a su vastedad excede los objetivos del presente texto. Sobre el tema se puede ver: S se puede ver: SILVESTRI, GRACIELA y ALIATA, 2001; COSGROVE, DENIS, industrialización y el mejoramiento de la producción agropecuaria pasan a ser considerados como problemas convergentes, articulados, y de resolución conjunta mediante planes" (MAzzA, 2008:52).

Hacia 1942, la Revista de Arquitectura publica un artículo de MaUricio CravotTo en el que expone la necesidad de concebir el territorio sobre la base de la noción de región y de recurrir al urbanismo regional para la resolución de ciertas cuestiones que los procesos urbanos del momento estaban demandando, por ejemplo, la relación ciudad-campo, o como lo explicita Cravotto, la relación "entre agro y urbe"117 (CRAVOTto, 1942).

En 1946, y ya con la experiencia de la reconstrucción de San Juan, Pastor ${ }^{18}$ publica el libro Urbanismo con Planeamiento. Allí, Pastor intenta definir una región de planeamiento, específicamente disciplinar, es decir, ni geográfica, ni geoeconómica, ni folclórica. En esta indagación recurre al concepto de paisaje cultural ${ }^{19}$, tomado de lo que podría llamarse el giro geopolitico que los estudios socioterritoriales adoptaron luego de la $2^{\underline{0}}$ Guerra Mundial (PASTOR,1946).

Incluso por fuera de la disciplina urbanística, el escritor CANAL Feıjoó, en 1945, hablará de una "palabra que pugna por salir (...). La palabra región resulta así algo mucho más amplio que el hecho politico provincial. La regionalización es trascendencia natural y racional de la provincia." (FEJJO, 1945).

En cuanto a Santa Fe, el diario El Litoral del 7 de julio de 1946 publicará un artículo firmado por su mismo director, SALVADOR CAPUTTO, en el cual se exponen algunas ideas, aunque con cierta vaguedad, sobre el concepto de región, entendido no como unidad geográfica en relación con un determinado recurso natural o elemento físico natural, sino como una unidad territorio-cultural. CAPPUTO reflexiona sobre la región en tanto espacio de inserción y componente espacial de la cultura de una comunidad, y expresa la necesidad de reconocer lo que él llama "originalidad" de cada región cultural (CAPUTTO, 1946:4).

Sin embargo, el concepto de región vinculado con la planificación será mencionado por CAPUTto recién en el año $1969^{20}$, en un artículo publicado con motivo del flamante túnel subfluvial Santa Fe-Paraná. En el artículo, CAPUTTO alerta sobre el criterio de regionalización que se está llevando adelante dentro del Plan del CONADE ${ }^{21}$, el cual considera que está produciendo divisiones que son "más técnicas que reales y más estadísticas que geográficas." (CAPUTTO, 1969:4). Y continuará más adelante: “... donde se arrasa con todo lo vital...”; finalizando el artículo 
Gisela Ariana Rausch

\section{EL PLAN DEL 80 EN SANTA FE: REGIONALIZACIÓN TARDÍA ANTE UNA SUBURBANIZACIÓN INMINENTE}

con la exposición de su opinión contraria a la adopción de la idea de región que circula en el país por ese momento y que según él “... es una copia extranjera que no tiene aplicación en nosotros". Finalmente, agrega: "En Francia, la regionalización, tiene su base en la centralización, que en nuestro país, no es conveniente" (CAPUTTO, 1969:4).

Puede verse entonces que el concepto de región entendido en relación con la planificación del territorio aparece en los medios, en Santa Fe, sobre finales de la década del 60, en paralelo con los trabajos que en 1966 iniciara la Oficina de Planeamiento y que decantaran, en 1980, en el Expediente del Plan Director. Y las críticas de CAPutTo iban dirigidas al carácter meramente tecnocrático con que se estaba llevando adelante el plan, inscrito dentro del Plan Nacional de Desarrollo, que era más un instrumento de centralización del poder nacional que una herramienta para el fortalecimiento de las regiones. Además, en lo que a definición de límites regionales se refiere, si de lo que se trataba con la regionalización era ir más allá de los tradicionales, y muchas veces rígidos, límites jurisdiccionales, el Plan del 80 se circunscribió al municipio de Santa Fe, sin traspasar ningún límite. Se hace referencia a la "región donde se ubica la ciudad de Santa Fe", pero luego se pasa a una caracterización del suelo y la topografía de la ciudad y su territorio circundante inmediato, perteneciente al ejido municipal. Lo mismo ocurre con las descripciones del clima y la hidrografía.

Si se busca en el expediente cuál es el concepto de región, se observa que no se trata de un Plan regional, sino un Plan para una ciudad (definida jurisdiccionalmente) que se inserta en una región, y que dicha región responde a la división que el Estado nacional ya ha definido en el Plan Nacional de Desarrollo que había propuesto el CONADE. De lo que se trata, entonces, es de integrar el Plan de la ciudad dentro de un cuerpo más amplio de obras y proyectos a nivel regional, provincial y nacional, ya prefiguradas dentro del Proyecto de la Cuenca del río Bermejo.

El expediente, entonces, se confecciona dando cuenta del lugar que la ciudad tiene en la región y describiendo sus áreas de influencia, tanto directas (localidades con continuidad física), como a nivel regional y nacional. Estas últimas se consideran de influencia sobre la base de relaciones económicas o por compartir algún recurso fluvial (que sin duda redunda en lo primero).

Frente al despliegue reflexivo que las décadas del 50 y 60 vieron florecer en la disciplina urbanística, el Plan del 80 aparece como una versión tardía, surgida de la inercia y pro-
20- En el diario El Litoral, con respecto al término "región", entre 1920 y 1980 aparecen numerosos artículos desde principios de siglo que utilizan la palabra de una manera muy vaga: en ocasiones para significar una porción de territorio relacionado con un recurso natural (un río una montaña), otras veces un
área con determinada actividad área con determinada actividad
económica; incluso, llegó a nomeconómica; incluso, llegó a nom-
brarse como región la comuna de Santa Rosa, perteneciente al departamento Garay.

21- Siglas de Consejo Nacional de Desarrollo. 


\section{Artículos Arbitrados}

CUADERNO URBANO. Espacio, Cultura, Sociedad - VOL. 9 - № 9 (Octubre 2010) pp. 111-129. ISNN 1666-6186

$\overline{\text { 22- Se prohibió, por ejemplo, el }}$ ingreso de vehículos de tracción a sangre, la construcción de viviendas precarias, se pintaron de blanco los cordones de las veredas, etc. (Alonso y Citroni, 2008:82-83)

23- Entrevista realizada el 15 de marzo de 2010.

24- ALONSO y CITRONI, 2008. ducto de la burocracia municipal. El fruto de un trabajo automático que un equipo de técnicos llevará adelante en una oficina que con los años irá perdiendo capacidad de actuación y presencia, en estrecha relación con la voluntad de los sucesivos gobiernos.

\section{EL PLAN Y LA HISTORIA QUE NO SE ASUME}

Resulta interesante detenerse sobre dos cuestiones que por estar al final no dejan de ser centrales, o al menos, activadoras de próximas indagaciones. En principio, surge la pregunta acerca de las motivaciones y urgencias que puede haber tenido un gobierno de facto para publicar un plan con ideas de dos y tres décadas anteriores y que forma parte de un proyecto regional que nunca dio pasos adelante.

La pregunta quizás pueda comenzar a ser resuelta si nos remitimos al clima social y político de la ciudad en los últimos años de la década del 70. Alonso y CiTroni observan que el gobierno militar, entre los años 1976 y 1983, lleva adelante una serie de reformas urbanas que, dando continuidad a tendencias previas, intentan recuperar una ciudad limpia, ordenada y tranquila (Alonso y Citrons, 2008:80). Desde 1976, el gobierno del coronel Coquet inicia una serie de intervenciones urbanas, como la peatonal San Martín, proyecto que había sido elaborado en la Oficina de Planeamiento una década antes, y una serie de reformas respecto del funcionamiento de la ciudad que se tradujeron en la implementación de ordenanzas que mantenían el orden público ${ }^{22}$ y que habían sido adoptadas, según menciona CITRONI ${ }^{23}$, del gobierno de facto anterior.

Así mismo, el formulado proyecto hidroeléctrico Paraná Medio forzaba, de algún modo, a realizar una reestructuración de las comunicaciones (vial y ferroviaria) de la ciudad y una revisión de sus patrones de crecimiento. Sumado a esto, CITRONI $^{24}$ considera que existía cierta presión hacia el gobierno para que saliera a la luz el tan promocionado y largamente esperado plan urbano. Por lo cual, cobra cierto sentido la urgencia que, ante la presión de los medios y la necesidad de hacer visible la voluntad de cambio, lleva al gobierno de facto, en 1980, a publicar un plan que había sido elaborado en su mayor parte con formulaciones de principios de los 70 , con ideas notablemente desfasadas respecto del momento histórico, más aún, intentando capturar la situación del momento con herramientas y propuestas de décadas anteriores.

La otra cuestión tiene que ver con una problemática importante en la ciudad de Santa Fe, la cual, por su ubicación en medio de dos sistemas hídricos importantes —el del río Paraná 
Gisela Ariana Rausch

\author{
EL PLAN DEL 80 EN SANTA FE: REGIONALIZACIÓN TARDÍA ANTE UNA \\ SUBURBANIZACIÓN INMINENTE
}

y el del río Salado - ha sufrido históricamente recurrentes inundaciones, principalmente provenientes del río Paraná ${ }^{25}$. Si bien se trata de un fenómeno normal, es decir, todo río inunda periódicamente su valle, la ocupación urbana del valle aluvial - que en Santa Fe ha venido cobrando dimensiones preocupantes desde la década del 90 - ha agravado el fenómeno. En este sentido, la inundación se ha convertido en un problema urbano en estrecha relación con el modo en que se ha ido ocupando el valle, tanto con residencias como con obras de infraestructuras que muchas veces bloquean el escurrimiento del agua, tanto en épocas de crecida como en los meses de grandes lluvias, además de estar ubicadas en un área hídricamente crítica.

Así, la idea de extender la ciudad hacia el Este, que el Plan del 80 si no proponía, al menos, aceptaba de las formulaciones del llamado Plan Nardi, sin duda se ha cumplido, pero con la forma de una pesadilla. La población, desde la inauguración del anillo defensivo contra inundaciones, en 1994, no ha dejado de $\operatorname{crecer}^{26}$, y en mayor grado lo han hecho las edificaciones. Crecimiento que se ha estacionado en los últimos cinco años ${ }^{27}$.

Vale recordar que una Ordenanza Municipal de 1959 abrió paso a una urbanización de excepción, ya que dejaba sin efecto una anterior que exigía una serie de condiciones a los loteos con el fin de controlar la ocupación del albardón. Al suceder esto y no promulgarse una ordenanza que estableciera cierto control, se inició un proceso especulativo de subdivisión de la tierra que luego la construcción de la defensa profundizará notablemente.

Así, a diferencia de la urbanización que proponía el plan, se ha llevado adelante un loteo indiscriminado de tierras que el mercado inmobiliario se ha encargado de promocionar apelando a valores de amplia difusión, como la seguridad de vivir fuera del centro urbano $y$ el privilegio que supone socialmente la vida en contacto con la naturaleza. Se ha montado, en una zona con escasos rastros de urbanización ${ }^{28}$, un enclave residencial donde pretenciosas residencias que parecieran haber sido recortadas de un barrio privado se han instalado, en un área de notable precariedad urbana y alto riesgo hídrico ${ }^{29}$. (Imágenes 6 y 7 )

Resulta interesante para comparar y reflexionar sobre esta cuestión lo ocurrido en Resistencia respecto de la ocupación de áreas inundables, cuestión que será denunciada en 1983 por BRIAn THOMPSON ${ }^{30}$ desde su exilio forzado, en una nota enviada al diario Clarín. Thompson se refiere allí al loteo indiscriminado que "sectores vinculados a la especulación inmo-

25- Las crecidas del Paraná cons tituyeron uno de los motivadores principales para su traslado y segunda fundación en 1660 al actual emplazamiento.

26- Entre 1991 y 2001 el área que co- Entre 1991 y 2001 el área que
corrende a los distritos de la corresponde a los distritos de la
costa tuvo un porcentaje de crecicosta tuvo un porcentaje de creci-
miento mayor al $30 \%$, mientras que la ciudad de Santa Fe lo hizo en poco más del $4 \%$.

27- Puede afirmarse esto observando datos censales del INDEC vando datos censales del INDEC
de los años 1980, 1991 y 2001, y de los años 1980, 1991 y 2001, y
relevamientos catastrales de las relevamientos catastrales de las
últimas tres décadas, las cuales dan cuenta de una "meseta" en lo que a subdivisión y edificación se refiere.

28- No existe equipamiento básico urbano, las calles no están pavimentadas, no hay desagües pluviales, ni servicios básicos, como red de gas y teléfono; incluso en algunas zonas no hay alumbrado público.

29- En el año 2007, 400mm de lluvia provocaron la inundación de una zona importante dentro del área "protegida", y a principios de 2010 , en presencia de una crecida preocupante del río Paraná, que superó los niveles de máximos definidos como "de evacuación", las residencias de las zonas más altas dentro de la defensa tenían filtraciones de agua provenientes
de las napas que habian subido a de las napas que habian
la superficie del suelo. 


\section{Artículos Arbitrados}

CUADERNO URBANO. Espacio, Cultura, Sociedad - VOL. 9 - № 9 (Octubre 2010) pp. 111-129. ISNN 1666-6186

30- Director del Departamento de Planeamiento de la UNNE entre 1966 y 1974.

\section{1- El trabajo interdisciplinario} se realizó entre 1968 y 1973.
6 y 7-Residencias en Villa California y Colastiné Norte, en el área de la costa de la ciudad Fuente: Guía Inmobiliaria, $N^{\circ}$
40 y 41 . CIC. Santa Fe. 2008. biliaria" (THOMPson, 1983) estaban llevando adelante en áreas de alto riesgo hídrico, ya estudiadas y consideradas no aptas para urbanización por el Departamento de Planeamiento de la UNNE en un trabajo realizado sobre Resistencia y su área de influencia. ${ }^{31}$ Se dejaba en claro en tal trabajo que las obras de defensa propuestas por el Plan Cotta no impli-
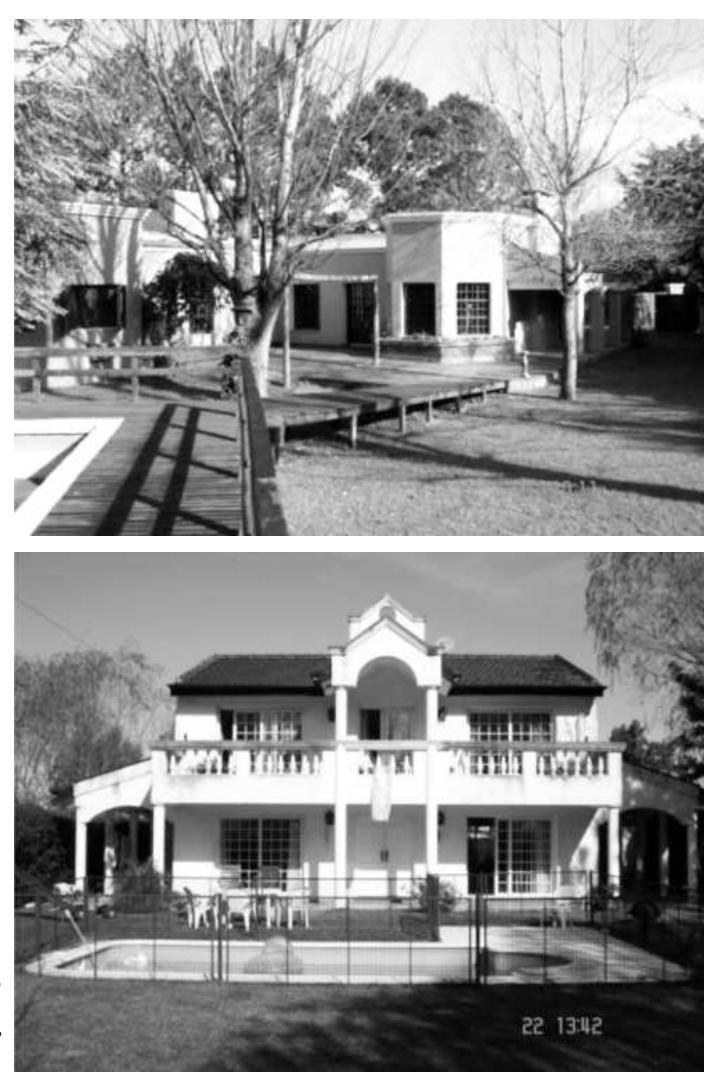
carían la extensión urbana hacia esas áreas, sino la protección de lo ya ocupado, dado que las defensas sólo debían "concebirse como protección a lo ya construido" y no como una obra que daría vía libre a la ocupación.

Una década después de su publica ción, y frente a las consecuencias de la ocupación indiscriminada de zonas inundables, THOMPSON recuerda el tra bajo y la "oscuridad" en la que fue colocado durante las gestiones políticas que siguieron a 1973.

Puede decirse, y ya sobre el final, que este trabajo no ha surgido meramente para rescatar aquello que se ha olvidado y traerlo al presente como una pieza de anticuario, sobre todo porque el Plan del 80 está muy lejos de ser una pieza preciosa a la que se tienen deseos de volver. Pero que dejemos en el olvido aquello que es preferible no ver para nada implica que no exista, ya que el pasado, en tanto no es asumido y aceptado, no dejará de insistir y subsistir. El Plan del 80 pone en cuestión una serie de problemáticas urbanas que hoy, a casi tres décadas, en la ciudad de Santa Fe siguen sin asumirse (mucho menos resolverse). 
Gisela Ariana Rausch

\section{EL PLAN DEL 80 EN SANTA FE: REGIONALIZACIÓN TARDÍA ANTE UNA SUBURBANIZACIÓN INMINENTE}

Por un lado, en el ámbito estrictamente disciplinar y de la historia de la disciplina, no se ha asumido la trascendencia que ha tenido el gobierno militar en la construcción del espacio urbano santafesino. Las normas urbanas fueron establecidas por este gobierno y el plan del 80 les dará plena legitimidad hasta nuestros días. Además, existen escasos trabajos sobre historia de la arquitectura y de la ciudad que se aboquen a tal período.

Por otro lado, está la cuestión de la ocupación del valle aluvial, la cual ha sido "resuelta" por el mercado inmobiliario con la más absoluta ausencia de políticas públicas. En el caso de la refuncionalización del puerto, por poner otro ejemplo, la ausencia del gobierno municipal en las decisiones dio lugar a que un área de relevancia por su valor simbólico y patrimonial arquitectónico quede segregada del centro urbano, con espacio público de escasa calidad, donde se ubican sin un ordenamiento coherente algunas construcciones de carácter comercial y recreativo privado, como el casino, en medio de amplias playas de estacionamiento vehicular.

En cuanto al Plan del 80, según se intentó aquí de dar cuenta, se formuló en una precariedad operativa y ligereza proyectual que difícilmente podrían haber superado la instancia de formulación. Su aparición tardía, sobre la que aún quedan cuestiones para seguir indagando, dio paso a la rapidez de su olvido. Sin embargo, no puede dejar de verse en la propuesta la intención de asumir de manera global y sistemática problemáticas urbanas que hoy pueden pensarse como ineludibles, dadas las condiciones históricas que esta última fase del capitalismo ${ }^{32}$ ha determinado para las ciudades marcadas profundamente por las fragmentaciones socioterritoriales, por el desarrollo desigual, por el acelerado consumo de recursos naturales básicos (agua, suelo, petróleo), entre otras cuestiones.

Pensar que planificar la ciudad va resolver todos los problemas y evitar el destino trágico que el régimen de acumulación capitalista ha delineado sin duda es una posición idealista si se piensa desde las experiencias en la disciplina, en tanto las urbanizaciones, en permanente transformación y complejización, no pueden ser pensadas (mucho menos transformadas) únicamente desde un saber disciplinar, sino más bien desde una multiplicidad de saberes en relación. Pero pensar lo contrario y dejar que la ciudad se desarrolle "libremente" es dar paso a la tiranía del mercado y a su poderosa fuerza estratificadora cuya única lógica posible pareciera ser la del beneficio económico de un grupo social cada vez más reducido y más poderoso.

\author{
32- Se hace referencia a la últi- \\ ma etapa de reestructuración \\ capitalista, en la cual se ha vuel- \\ to ineludible la atención sobre las \\ transformaciones territoriales \\ dada la magnitud, dimensión e \\ dada la magnitud, dimensión e \\ incluso situación crítica que és- \\ tas han cobrado en relación con \\ procesos que sin lugar a duda. \\ pueden rastrearse desde los ini- \\ cios del capitalismo. Ver: HARVEY, \\ D., 2001.
}




\section{Artículos Arbitrados}

CUADERNO URBANO. Espacio, Cultura, Sociedad - VOL. 9 - № 9 (Octubre 2010) pp. 111-129. ISNN 1666-6186

\section{BIBLIOGRAFÍA}

ALONSO, Luciano y CITRONI, Julieta (2008). "Intervenciones en la zona céntrica santafesina en época de dictadura: interacciones y conflictos". En: revista Cuaderno Urbano: Espacio, cultura y sociedad, №7. Nobuko/EUDENE, Resistencia.

ANDERMANN, Jens (2008). "Paisaje: imagen, entorno, ensamble". En: revista Orbis Tertius № XIII (14). Centro de Estudios de Teoría y Crítica Literaria. Facultad de Humanidades y Ciencias de la Educación (UNLP), La Plata.

ARÓSTEGUI, Julio (2004) La historia vivida. Sobre la historia del presente. Alianza, Madrid.

ARÓSTEGUI, Julio; BUCHRUCKER, Cristian y SABORIDO, Jorge (2001) El mundo contemporáneo: historia y problemas. Biblós, Buenos Aires.

CANAL FEIJOO, Bernardo (1945). "De una estructura regional". En: diario La Nación. Buenos Aires, 2 de setiembre de 1945.

CAPUTTO, Salvador (1946) "La región como centro de cultura”. En: Diario El Litoral. Santa Fe, 7 de Julio de 1946.

CAPUTTO, Salvador (1969). "Región y provincias". En: Diario El Litoral. Santa Fe, 4 de Julio de 1969.

COSGROVE, Denis (2002). "Observando la naturaleza: el paisaje y el sentido europeo de la vista”. En: Boletín de la AGE; № 34, España.

CRAVOTTO, M. (1942). "¿Qué quiere decir Instituto de Urbanismo de la Facultad de Arquitectura?". En: Revista de Arquitectura, № 259. Buenos Aires.

DE CERTEAU, M. (2000) La invención de lo cotidiano: las artes de hacer. Tomo I. Universidad Iberoamericana, México (1º edición de 1990).

FEDELE, Javier (2009). Ciudad y río: la construcción histórica de un paisaje. Tesis doctoral. Programa de Doctorado Teoría e Historia de la Arquitectura, Universitat Politecnica de Catalunya, Barcelona.

HARVEY, David. 2001 Espacios del Capital. Hacia una Geografía crítica. Madrid, Akal.

KOSELLECK, Reinhart (1993) Futuro Pasado. Para una semántica de los tiempos históricos. Paidós Básica, Barcelona.

MAZZA, Carlos Jerónimo (2008). "De lo sublime a lo técnico: la incorporación de la noción de paisaje en el Planeamiento Regiona en Argentina". En: revista Urban Perspectives, № 9. UPC, Barcelona.

PASTOR, José (1946) Urbanismo con Planeamiento. Principios de una nueva técnica social. Arte, Buenos Aires.

PASTOR, José (1946) San Juan, piedra de toque del planeamiento nacional. Arte y Técnica, Buenos Aires. 
Gisela Ariana Rausch

\section{EL PLAN DEL 80 EN SANTA FE: REGIONALIZACIÓN TARDÍA ANTE UNA SUBURBANIZACIÓN INMINENTE}

RIGOTTI, Ana María. (2003) Las invenciones del Urbanismo en Argentina (1900-1960). Tesis doctoral. Facultad de Arquitectura, Planeamiento y Diseño, Universidad Nacional de Rosario, Argentina.

SICA, Paolo (1981) Historia del Urbanismo, Vol. l.Instituto de Administración Local, Madrid. SILVESTRI, Graciela y ALIATA, Fernando (2001) El paisaje como cifra de armonía. Claves, Buenos Aires.

\section{Fuentes documentales}

Diario El Litoral. Domingo 7 de julio de 1946, Santa Fe.

Diario El Litoral. Viernes 4 de julio de 1969, Santa Fe.

Diario Norte. Lunes 15 de agosto de 1983. Resistencia, Chaco.

Plan Regulador de la ciudad de Santa Fe (1947). Miguel C. Roca. Instituto Argentino de Urbanismo, Buenos Aires.

Plan director de la ciudad de Santa Fe (1980). Dirección de Planeamiento Urbano y Proyectos, Municipalidad de Santa Fe. Publicación oficial, Santa Fe.

\section{Otras fuentes}

Entrevista realizada al arquitecto Waldemar Giacomino, co-fundador de la Oficina de Planeamiento de la municipalidad de Santa Fe (1966-1974) y Director de Servicios Públicos. Santa Fe, 2010.

Entrevista realizada al arquitecto Luis Amavet, integrante del equipo de trabajo en el Plan Director de Santa Fe, 1980. Santa Fe, 2010.

Entrevista realizada a Julieta Citroni, investigadora en Historia, de la Facultad de Humanidades y Ciencias, Universidad Nacional del Litoral. Santa Fe, 2010

CIC. Guía Inmobiliaria. №39. Santa Fe, marzo 2008.

CIC. Guía Inmobiliaria. № 40. Santa Fe, abril 2008.

CIC. Guía Inmobiliaria. № 4l. Santa Fe, mayo 2008. 
|

$\overline{\overline{7}_{1}}$

$\mid \vec{\Gamma}$ 